\title{
Dysregulation of over-expressed IL-32 in colorectal cancer induces metastasis
}

\author{
Yi Yang ${ }^{\dagger}$, Zihao Wang $^{\dagger}$, Yiming Zhou ${ }^{\dagger}$, Xiaoxiao Wang, Jianbin Xiang $^{*}$ and Zongyou Chen ${ }^{*}$
}

\begin{abstract}
Background: Interleukin (IL)-32 is a described intracellular pluripotent pro-inflammatory mediator, characterized by the signaling of NF-KB and STAT3.

Methods: Our study investigated whether IL-32 expression has clinical significance in the metastases of colorectal cancer (CRC). A total of 70 CRC patients were enrolled, 47 cases of which were single CRC organic metastasis lesions while the rest of which were primary CRC lesions (T4NxM0). IL-32 expression was detected by immunohistochemistry, and the correlation between IL-32 expression and CRC metastases was analyzed.

Results: The positive rates of IL-32 in the CRC organic metastasis group were more severe than those in the primary CRC group $(P<0.05)$. The positive rate of IL-32 in primary CRC with lymph node metastasis was more severe than that of IL-32 in primary CRC without lymph node metastasis $(P<0.05)$.

Conclusions: The level of IL-32 expression could influence the $N$ grade of CRC. Thus, IL-32 expression may stimulate the organic metastasis and the lymph node metastasis of CRC.
\end{abstract}

Keywords: IL-32, Colorectal cancer, Metastasis

\section{Background}

Colorectal cancer (CRC) is the one of the most common malignancy tumor worldwide and the fourth common cause of death of cancer [1]. It is estimated that CRC will cause more than 500,000 all over the world in 2013 [2]. A large amount of patients are initially diagnosed with develop stage IV CRC [3]. With the therapeutic development for CRC, the overall survival keeps on increasing, but the treatment of patients with metastasized CRC still remains a challenge $[4,5]$, and the underlying mechanism is actually unsolved [6,7]. As a result, it is always the main focus of clinical medicine to find the biomarker of CRC metastasis.

Cytokines are known to be involved in not only inflammation but also tumor development and progression [8]. Several researches have suggested that many cytokines (such as IL-10, IL-17, IL-22, IL-23, and IL-35) may have clinical significance in CRC [9-11].Interleukin-

\footnotetext{
* Correspondence: 07301010200@fudan.edu.cn; zongyouchen@hotmail.com ${ }^{\dagger}$ Equal contributors

Department of General Surgery, Huashan Hospital Affiliated to Fudan

University, Floor 16, Building 2, 12 Wulumuqizhong Road, Shanghai 200040, China
}

\section{Biomed Central}

32 (IL-32) is recognized as an intracellular pluripotent pro-inflammatory mediator firstly [12]. IL-32 can stimulate immunosuppressive immunocytes and lead to the raising of various cytokine expressions in stromal cells [13-15]. And soon, it was confirmed to be the promoted factor in the carcinogenesis of several solid tumors, such as gastric cancer, pancreatic cancer, and lung cancer [16-18].However, its expression has not been reported in CRC metastasis. In our study, IL-32 expression in cancer cells was immunohistologically evaluated, and the clinical implications of IL-32 positivity with CRC metastasis were analyzed and discussed.

\section{Methods}

\section{Patients and specimens}

We retrospectively collected 70 consecutive patients with CRC, 47 cases of which were CRC organic metastasis lesions while the rest of which were primary CRC lesions (T4NxM0). All of them underwent surgery from 2000 to 2013 at Huashan Hospital, Fudan Uni- 
Table 1 Clinical characteristics of the selected patients $(N=70)$

\begin{tabular}{lll}
\hline & N & $\%$ \\
\hline Gender & 33 & \\
Male & 37 & 47.14 \\
Female & & 52.86 \\
Position of lesions & 23 & $32.86^{\text {a }}$ \\
Primary lesions & 19 & $27.24^{\text {a }}$ \\
Brain & 11 & $15.71^{\text {a }}$ \\
Liver & 17 & $24.29^{a}$ \\
Other distant metastasis &
\end{tabular}

${ }^{a}$ The rate is calculated on the metastasis population.

versity, Shanghai, China. None of them received preoperative chemotherapy. The patient private identification information was deleted, and informed consent was obtained from all the patients. Clinical factors were assessed by the Medical Ethics Committee of Huashan Hospital.

\section{Immunohistochemistry}

From paraffin blocks, the selected tissue was assessed on $4-\mu \mathrm{m}$ sections on an automatic platform (Dako Immunostainer RM2145, Dako Corp., Copenhagen, USA). The samples were obtained from the $70 \mathrm{pa}-$ tients. Antigen retrieval was finished by microwaving in $10 \mathrm{~mm}$ citric acid monohydrate for $1 \times 5 \mathrm{~min}$ at $900 \mathrm{~W}$ and for $3 \times 5 \mathrm{~min}$ at $600 \mathrm{~W}$. Sections were treated with $0.3 \% \mathrm{H} 2 \mathrm{O} 2$ for $30 \mathrm{~min}$ in order to block endogenous tissue peroxidase. The reaction was visualized by the Envision kit (Dako Corp., Copenhagen, Denmark) for IL-32 (ab37158, Abcam, Tokyo, Japan). The antibody was obtained from R\&D Systems and used at the dilution of 1:200, being incubated with the tissue sections at $37^{\circ} \mathrm{C}$ for $1 \mathrm{~h}$. Splenic tissue was used as a positive control for IL-32 expression. The positive control was included in each run. The optical density (OD) value of the tumor cell staining was measured for quantitative analysis.
Three experienced pathologists independently evaluated IL-32-stained slides without the knowledge of patient clinicopathologic information. The intensity and percentage of immunoreactivity was scored on a scale of 0 to $3+$. Membrane staining in less than $10 \%$ of invasive tumor cells was scored as 0 ; faint/barely perceptive membrane staining was detected in $10 \%$ of tumor cells was scored as 1+; weak to moderate complete reactivity in more than $10 \%$ tumor cells or $<30 \%$ was scored as $2+$; strong complete reactivity in $10 \%$ or more of tumor cells was scored as $3+$. A score of 0 or $1+$ was considered negative while scores $2+$ and $3+$ were positive.

\section{Statistical analysis}

Statistical analysis was performed by $\chi 2$ tests, and the results are considered to be statistically significantly different when $P$ value is less than 0.05 . The frequencies of variables are described in percentages. All analyses are performed using the SPSS version 19.0 software for Windows (SPSS Inc., Chicago, IL, USA).

\section{Results \\ Samples}

All 70 CRC patients were considered eligible and included in our analysis. Median age at time of metastasis resection or radical operation was 61 years (41 to 87); $47.14 \%$ patients were males and $52.86 \%$ females. The cases with other organic metastases include seven cases of peritoneal metastasis, four cases of ovarian metastases, three cases of great omentum metastasis, one case of gum metastasis, one case of osseous metastasis, and one case of bladder metastasis. Patients' clinical characteristics are summarized in Table 1.

The relationship between IL-32 and organic metastasis of CRC Immunohistochemistry (IHC) IL-32 expression pattern is described in Table 2: 22 cases score 0 (31.44\%), 12 cases score $1+(17.14 \%), 18$ cases score $2+(25.71 \%)$, and 18 cases score $3+(25.71 \%)$. Figure 1 shows the comparison of the IHC slides for IL-32.

Here, IHC IL-32 expression pattern of primary lesions is compared with brain metastasis, liver metastasis, and other metastasis. The results were considered to be

Table 2 IL-32 expression and immunohistochemical score of primary lesions and other metastasis

\begin{tabular}{|c|c|c|c|c|c|c|c|c|}
\hline \multirow[t]{2}{*}{ IL-32 } & \multicolumn{2}{|c|}{ Primary lesions } & \multicolumn{2}{|c|}{ Brain metastasis } & \multicolumn{2}{|c|}{ Liver metastasis } & \multicolumn{2}{|c|}{ Other distant metastasis } \\
\hline & $N$ & $\%$ & $N$ & $\%$ & $N$ & $\%$ & $N$ & $\%$ \\
\hline 0 & 9 & 39.13 & 5 & 26.32 & 1 & 9.10 & 7 & 41.18 \\
\hline $1+$ & 7 & 30.43 & 2 & 10.52 & 3 & 27.27 & 0 & 0.00 \\
\hline $2+$ & 2 & 8.70 & 5 & 26.32 & 3 & 27.27 & 8 & 47.06 \\
\hline $3+$ & 5 & 21.74 & 7 & 36.84 & 4 & 36.36 & 2 & 11.76 \\
\hline
\end{tabular}




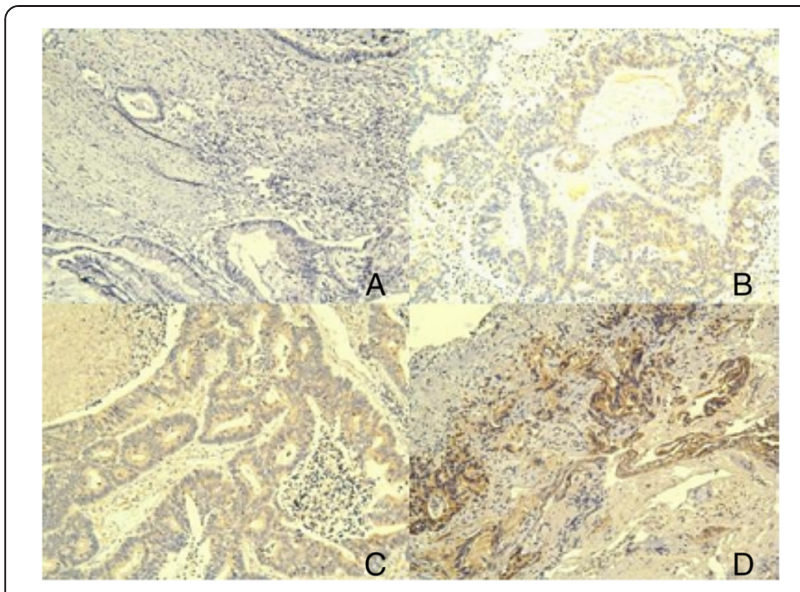

Figure $1 \mathrm{lL}-32$ staining scored 0 (A); IL-32 staining scored 1+ (B); IL-32 staining scored $2+(C)$; and IL-32 staining scored $3+$ (D) magnification $\times 100$.

statistically significantly different $(P<0.05)$, respectively, (Table 3).

The relationship between IL-32 and lymph node metastasis of CRC

Here, IHC IL-32 expression pattern of primary lesions with no lymph node metastasis was compared with primary lesions with lymph node metastasis. The results were considered to be statistically significantly different $(P<0.05)$, respectively, (Table 4$)$.

Here, the main OD values of different grades of lymph node metastasis ( $N$ grade, according to NCCN colorectal cancer practice guideline 2012) were compared altogether. The results showed that the OD value had the trend of rising with the level-up of $N$ grade (Table 5, Figure 2).

\section{Discussions}

Several researches suggested that cytokines may be involved in the proliferation, metastasis, and preventing from antitumor cellular immunity [19-21]. Recent study showed that IL-32 can affect the signaling of NF- $\mathrm{KB}$ and STAT3 [22-24], which are confirmed to be the antiapoptotic and pro-angiogenic genes in cancer development

Table 3 Comparison of IL-32 expression between primary lesions and different metastases of CRC

\begin{tabular}{llll}
\hline Samples & Positive $\boldsymbol{N ( \% )}$ & Negative $\boldsymbol{N ( \% )}$ & $\boldsymbol{P}$ value \\
\hline Primary lesions & $7(30.44)$ & $16(69.56)$ & 0.0103 \\
Brain metastasis & $12(63.16)$ & $7(36.84)$ & \\
Primary lesions & $7(30.44)$ & $16(69.56)$ & 0.0013 \\
Liver metastasis & $7(63.63)$ & $4(36.37)$ & \\
Primary lesions & $7(30.44)$ & $16(69.56)$ & 0.0102 \\
Other distant metastasis & $10(58.82)$ & $7(41.18)$ & \\
\hline
\end{tabular}

Table 4 Comparison of IL-32 expression between $\mathrm{N}-/ \mathrm{N}+$ primary lesions of CRC

\begin{tabular}{lllr}
\hline Samples & Positive $\boldsymbol{N ( \% )}$ & Negative $\boldsymbol{N ( \% )}$ & $\boldsymbol{P}$ value \\
\hline No lymph node metastasis & $1(7.69)$ & $12(92.21)$ & 0.0000 \\
Lymph node metastasis & $6(60)$ & $4(40)$ & \\
\hline
\end{tabular}

[25]. Carmi et al. [26] suggested that IL-32 can promote angiogenesis and counterbalance the inflammation and antitumor immunity. Seo et al. [27] measured serum IL32 levels of gastric cancer by ELISA and immunostaining, finding significantly higher levels of IL-32 to those of healthy volunteers. In this study, we demonstrate the association of between IL-32 and different metastases of $\mathrm{CRC}$, aiming at finding new therapeutic direction for CRC metastasis.

\section{IL-32 and organic metastasis of CRC}

IL-32 expression in tumor cells has been confirmed mainly occurring in the advanced stages of cancers $[16,18]$. But the relationship between IL-32 status and CRC organic metastasis has not been clarified. Our research aimed to describe the influence of IL-32 on CRC organic metastasis, to compare the IL-32 expression in primary lesions or organic metastasis, so as to find the biological mark of CRC organic metastasis.

As determined by our analysis of 70 CRC patients, IL-32 expression correlated with the organic metastasis of CRC. The rate of IL-32-positive cases of CRC primary lesions was $30.4 \%$, while brain metastasis $63.16 \%$, liver metastasis $63.63 \%$, and other organic metastasis $58.82 \%$. The positive rates of CRC brain metastasis, liver metastasis, and other distant metastasis were similar. There were great differences between the results of the rate of IL-32-positive cases of CRC primary lesions and different organic metastases (Table 3). As a result, IL-32 supposed to be the nonspecific mark of CRC organic metastasis.

\section{IL-32 and lymph node metastasis of CRC}

It has been suggested that IL-32-positive expression was frequently associated with lymph node metastasis in gastric cancer and lung cancer $[16,18]$. But there is still no evidence whether there is association between IL-32 expression and CRC lymph node metastasis. Our research is here to analyze the IL-32

Table $5 \mathbf{N}$ grade of primary CRC and mean OD value

\begin{tabular}{llll}
\hline $\boldsymbol{N}$ grade & $\boldsymbol{N}$ & $\%$ & Mean OD value \\
\hline 0 & 13 & 56.52 & 10.31 \\
1 & 6 & 26.08 & 12.33 \\
2 & 2 & 8.70 & 14.50 \\
3 & 2 & 8.70 & 18.50 \\
\hline
\end{tabular}




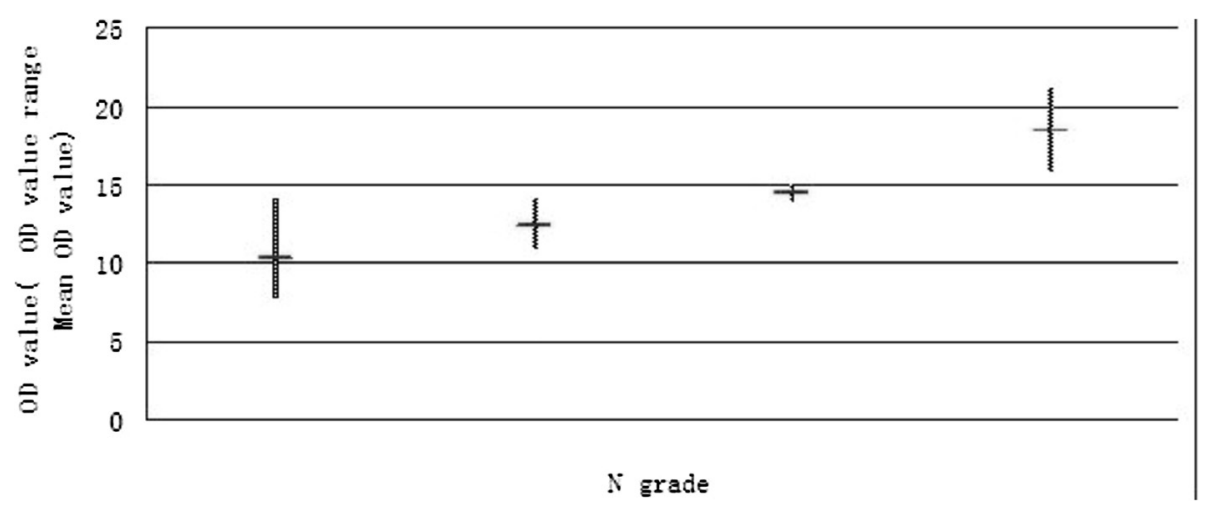

Figure $\mathbf{2}$ The relationship between $N$ grade of primary $C R C$ and $O D$ value.

expression staining in CRC samples (T4NxM0), so as to check whether IL-32 relates to CRC lymph node metastasis.

The result showed that the rate of IL-32-positive cases of CRC lymph node metastases was $60 \%$, much higher than those without lymph node metastasis. The results were considered to be statistically significantly different (Table 4). The tendency showed that the level of IL-32 expression may influence the $N$ grade of CRC (Table 5, Figure 2). Further study with larger sample size of the primary lesion population should be made for exactly evidence.

\section{Conclusions}

In conclusion, this research raises the concept of an important role of IL-32 in CRC. Over-expression of IL-32 may stimulate the organic metastasis and the lymph node metastasis of CRC. IL-32 was confirmed to be the biological mark for CRC metastasis. In $\mathrm{CRC}$, this result may promote the therapeutic potential for CRC metastasis. However, there are still several aspects of IL-32 remaining elusive. Our study also presents some limitations. The follow-up of the patients has not finished yet. Further analysis on larger populations is required to support the results of this study. And also, further researches should be taken out to clarify the underlying pathway of IL-32, so as to propose a new clinical therapy for CRC metastasis.

\section{Competing interests}

The authors declare that they have no competing interests.

\section{Authors' contributions}

$Y Y, Z W$, and $Y Z$ carried out the background studies and drafted the manuscript. $Y Y$ and $X W$ participated in the immunohistochemistry work and performed the statistical analysis. ZC and JX conceived of the study and participated in its design and coordination. All authors read and approved the final manuscript.

\section{Acknowledgements}

The authors want to thank Zude Xu, MD (Division of Pathology, Huashan Hospital, Shanghai, China) for his collaboration in providing the pathological specimens.

\section{Funding}

This study was supported by a grant from National Natural Science Foundation of China (no. 81201618) and a grant from Natural Science Foundation of Shanghai Municipal Science and Technology Commission (no. 134119a1400).

Received: 21 December 2014 Accepted: 16 March 2015

Published online: 12 April 2015

\section{References}

1. Jemal A, Bray F, Center MM, Ferlay J, Ward E, Forman D. Global cancer statistics. CA: Cancer J Clin. 2011;61C:69-90.

2. Siegel R, Naishadham D, Jemal A. Cancer statistics. CA Cancer J Clin. 2013;63:11-30.

3. Midgley R, Kerr D. Conventional cytotoxic and novel therapeutic concepts in colorectal cancer. Expert Opin Investig Drugs. 2001;10:1011-9.

4. Ferlay J, Shin HR, Bray F, Forman D, Mathers C. Estimates of worldwide burden of cancer in 2008: GLOBOCAN 2008. Int J Canc Suppl J Int Canc. 2010;127:2893-917.

5. Mitry E, Bouvier AM, Esteve J, Faivre J. Benefit of operative mortality reduction on colorectal cancer survival. Br J Surg. 2002;89:1557-62.

6. Sethi N, Kang Y. Unravelling the complexity of metastasis-molecular understanding and targeted therapies. Nat Rev Canc. 2011;11:735-48.

7. Wanebo HJ, LeGolvan M, Paty PB, Saha S, Zuber M. Meeting the biologic challenge of colorectal metastases. Clin Exp Metastasis. 2012;29:821-39.

8. Lin WW, Karin M. A cytokine-mediated link between innate immunity, inflammation, and cancer. J Clin Invest. 2007;117:1175-83.

9. Ting WC, Chen LM, Huang LC, Hour MJ, Lan YH, Lee HZ, et al. Impact of interleukin-10 gene polymorphisms on survival in patients with colorectal cancer. J Korean Med Sci. 2013;28(9):1302-6.

10. Petanidis S, Anestakis D, Argyraki M, Hadzopoulou-Cladaras M, Salifoglou A. Differential expression of IL-17, 22 and 23 in the progression of colorectal cancer in patients with K-ras mutation: Ras signal inhibition and crosstalk with GM-CSF and IFN- $\gamma$. PLoS One. 2013;8(9):e73616.

11. Zeng JC, Zhang Z, Li TY, Liang YF, Wang HM, Bao JJ, et al. Assessing the role of IL-35 in colorectal cancer progression and prognosis. Int J Clin Exp Pathol. 2013;6(9):1806-16.

12. Jung MY, Son MH, Kim SH, Cho D, Kim TS. IL-32gamma and Streptococcus pyogenes cell wall fragments synergise for IL-1-dependent destructive arthritis via upregulation of TLR-2 and NOD2. Ann Rheum Dis. 2010;69:1866-72.

13. Calabrese F, Baraldo S, Bazzan E, Lunardi F, Rea F, Maestrelli P, et al. IL-32, a novel proinflammatory cytokine in chronic obstructive pulmonary disease. Am J Respir Crit CareMed. 2008;178:894-901.

14. Kim SH, Han SY, Azam T, Yoon DY, Dinarello CA. Interleukin-32: a cytokine and inducer of TNF alpha. Immunity. 2005;22:131-42. 
15. Conti P, Youinou P, Theoharides TC. Modulation of autoimmunity by the latest interleukins (with special emphasis on IL-32). Autoimmun Rev. 2007;6:131-7.

16. Seo EH, Kang J, Kim KH, Cho MC, Lee S, Kim HJ, et al. Detection of expressed IL-32 in human stomach cancer using ELISA and immunostaining. J Microbiol Biotechnol. 2008;9:1606-12.

17. Nishida A, Andoh A, Inatomi O, Fujiyama Y. Interleukin-32 expression in the pancreas. J Biol Chem. 2009;284(26):17868-76.

18. Sorrentino C, Di Carlo E. Expression of IL-32 in human lung cancer is related to the histotype and metastatic phenotype. Am J Respir Crit Care Med. 2009;180(8):769-79.

19. Balkwill F, Mantovani A. Inflammation and cancer: back to Virchow? Lancet. 2001;357:539-45.

20. Ben-Baruch A. Inflammation-associated immune suppression in cancer: the roles played by cytokines, chemokines and additional mediators. Semin Cancer Biol. 2006;16:38-52.

21. Kim R, Emi M, Tanabe K, Arihiro K. Tumor-driven evolution of immunosuppressive networks during malignant progression. Cancer Res. 2006;66:5527-36.

22. Yun HM, Oh JH, Shim JH, Ban JO, Park KR, Kim JH, et al. Antitumor activity of IL-32 $\beta$ through the activation of lymphocytes, and the inactivation of NF-KB and STAT3 signals. Cell Death Dis. 2013;4:e640.

23. Yousif NG, Al-Amran FG, Hadi N, Lee J, Adrienne J. Expression of IL-32 modulates NF-KB and p38 MAP kinase pathways in human esophageal cancer. Cytokine. 2013;1(1):223-27.

24. Oh JH, Cho MC, Kim JH, Lee SY, Kim HJ, Park ES, et al. IL-32y inhibits cancer cell growth through inactivation of NF-KB and STAT3 signals. Oncogene. 2011;30(30):3345-59.

25. Lee H, Herrmann A, Deng JH, Kujawski M, Niu G, Li Z. Persistently activated Stat3 maintains constitutive NF-kappaB activity in tumors. Cancer cell. 2009;15:283-93.

26. Carmi Y, Rinott $G$, Dotan S, Elkabets M, Rider $P$, Voronov E, et al. Microenvironment-derived IL-1 and IL-17 interact in the control of lung metastasis. J Immunol. 2011;186:3462-71.

27. Seo EH, Kang J, Kim KH, Cho MC, Lee S, Kim HJ, et al. Detection of expressed IL-32 in human stomach cancer using ELISA and immunostaining. J Microbiol Biotechnol. 2008;18:1606-12.

\section{Submit your next manuscript to BioMed Central and take full advantage of:}

- Convenient online submission

- Thorough peer review

- No space constraints or color figure charges

- Immediate publication on acceptance

- Inclusion in PubMed, CAS, Scopus and Google Scholar

- Research which is freely available for redistribution 